\title{
Design of a Novel Wideband Low-Scattering Shared Aperture Metasurface
}

\author{
Tong HAN, Xiangyu CAO, Jun GAO, Yuejun ZHENG \\ Information and Navigation Institute of Air Force Engineering University, Xi'an, Shaanxi, 710077, China \\ 15594806122@163.com, xiangyucaokdy@163.com,gjgj9694@163.com, erikzhengyang@126.com \\ Submitted April 4, 2017 / Accepted August 7, 2017
}

\begin{abstract}
A novel shared aperture metasurface (SA-MS) for wideband radar cross section (RCS) reduction is designed and fabricated in this paper. The SA-MS is composed of a kind of perfect metamaterial absorber (PMA) and two kinds of artificial magnetic conductors (AMCs), where they share the same physical aperture in horizontal dimensionality with an aperiodic arrangement. Based on this design, the RCS reduction bandwidth of the SA-MS can be remarkably broadened due to the cascade connection of different working modes, which include absorption for the incidence of PMA and phase cancellation between three kinds of MS lattices. Simulation and measurement results indicate that a 3-dB RCS reduction is achieved from $4.98 \mathrm{GHz}$ to $14.14 \mathrm{GHz}(95.8 \%$ relative bandwidth) for both $x$ - and $y$-polarized incident waves and the 6-dB RCS reduction bands for the $x$ - and $y$ polarizations are $5.04 \mathrm{GHz}-13.02 \mathrm{GHz}, \quad 5.06-8.66 \mathrm{GHz}$ and $9.22 \mathrm{GHz}-12.12 \mathrm{GHz}$, respectively.
\end{abstract}

\section{Keywords}

Shared aperture metasurface, wideband, low-scattering

\section{Introduction}

With the development of electromagnetic stealth technology, researchers are paying more attention to the metasurface (MS) due to its excellent manipulation for electromagnetic waves. On a broad scale, electromagnetic band gap [1] (EBG), high impedance surface (HIS) [2], frequency selective surface (FSS) [3], [4], polarization rotation surface (PRS) [5], [6], artificial magnetic conductor (AMC) [7-10], perfect absorbing material (PMA) [11-14] and spoof surface plasmon polaritons (SSPP) [15], [16] could be classified into the category of MS, among which AMC (easy processing and flexible in manipulating the reflection phase) and PMA (extremely low profile) draw increasingly interest of the researchers.

On the one hand, the structure of AMC is first proposed by D. Sievenpiper in 1999 [7]. In 2007, based on the phase cancellation principle, Paquay proposed a MS composed of AMC and perfect electronic conductor (PEC) with a chessboard arrangement to achieve RCS reduction for the normal incidence [8]. However, the RCS reduction bandwidth is restricted because the bandwidth of AMC is limited and the reflection phase of PEC is a constant. To this end, Zhao [17] presented a MS composed of a single anisotropic element with an orthometric permutation and the $10 \mathrm{~dB}$ RCS reduction bandwidth is expanded to $32 \%$. In addition, Galarregui designed two different AMC unit cells to obtain an effective phase cancellation in a broader frequency band, the RCS reduction bandwidth is broadened as a result [18]. In 2016, Wan proposed an AMC unit cell loaded the pin diode to produce binary states of " 1 " or " 0 " and a broadband RCS reduction is obtained by controlling the states of AMC with different phase responses [19]. On the other hand, the research on PMA proposed by Landy started in 2008 [11], while the half-power bandwidth (HPBW) of PMA is usually less than 5\%. To expand the HPBW of PMA, Zou superimposed the different resonance modes within a lattice by placing different size of the units with an aperiodic arrangement and the HPBW is increased to $32 \%$ [20]. In addition, the multilayer structure [21] and loading lumped components [22] also give a path to broaden the HPBW of PMA. In summary, for the MS constructed by the elements of AMC, the key for RCS reduction lies in the utilization of reflection phase information to achieve phase cancellation, while it is the utilization of amplitude information for PMA to achieve perfect absorption for the incident wave. However, the RCS reduction bandwidth of the MS hasn't been broadened efficiently because the reflection phase information of $\mathrm{AMC}$ at low and high frequency bands is usually neglected and the reflection phase information of PMA is less taken into account in the existing literature.

In consideration of the situation, in this paper, we arrange a PMA lattice and two AMC lattices in a way of shared aperture with an aperiodic arrangement. In this way, not only both the amplitude and reflection phase information of PMA get a comprehensive utilization due to its absorption for the incident wave and phase cancellation with the two AMCs, but also the reflection phase information of the two AMCs gets a more efficient utilization at 
low and high frequency bands. As a result, the low-scattering bandwidth of the shared aperture metasurface (SA-MS) is dramatically broadened attributed to the cascade connection of multiple RCS reduction bands.

\section{Structures and Simulation Analysis of MS Unit Cells}

The unit cell of PMA is shown in Fig. 1(a). The structure was used to design low-RCS microstrip antenna because of extremely low-profile and insensitive to the polarization of the incident [12]. The top layer etched a rhombus-shaped gap in a metallic patch while the bottom layer is covered by the intact metallic patch. The middle layer is FR4 with a thickness of $0.5 \mathrm{~mm}$, a relative permittivity of 4.4 and a loss tangent of 0.02 . The two AMCs both are composed of two metallic layers separated by a dielectric substrate with a thickness of $3 \mathrm{~mm}$, a relative permittivity of 2.65 and a loss tangent of 0.001 . The difference between two AMCs lies in the upper layer, where it is a square patch for AMC1 while it is composed of two different sizes of patches in a chessboard arrangement for AMC2. Table 1 gives the specific structure dimensions of the three MS unit cells.

As shown in Fig. 2, the reflection characteristics of the MS unit cells are calculated by HFSS14.0, which is based on the Floquet port and master/slave boundary conditions to simulate the infinite periodic units. From Fig. 2(a), reflection amplitude of the PMA is almost 0 at 5.1 GHz, indicating its impedance is matched to free space and achieving perfect absorption for the incident wave. At the same time, the two AMCs both show total reflection for the incident wave at the range of $4.5 \mathrm{GHz}-15.5 \mathrm{GHz}$. In addition, the in-phase reflection bands $\left(-90^{\circ}<\right.$ reflection phase $<+90^{\circ}$ ) for both AMC1 and AMC2 are $5.12 \mathrm{GHz}-$ $7.36 \mathrm{GHz}$ and $8.32 \mathrm{GHz}-15.5 \mathrm{GHz}$ and the corresponding 0 -phase frequencies are $6.16 \mathrm{GHz}$ and $11.78 \mathrm{GHz}$, respectively, while the frequency is consistent with the resonant frequency for PMA.

Figure 3 gives the phase difference curves of the three MS unit cells, where $\Delta \varphi_{1}, \Delta \varphi_{2}$ and $\Delta \varphi_{3}$ represent the phase differences between AMC1 and AMC2, PMA and AMC1, and PMA and AMC2, respectively. A black dashed line of which $\Delta \varphi=180^{\circ}$ is intersected with the three curves at point of $P i(i=1,2,3,4,5)$, and the corresponding frequency points are $f_{i}=\left[f_{1}, f_{2}, f_{3}, f_{4}, f_{5}\right]=[5.10 \mathrm{GHz}$, $6.13 \mathrm{GHz}, 6.91 \mathrm{GHz}, 10.59 \mathrm{GHz}, 12.01 \mathrm{GHz}$. To simplify the expression, the unit cells of PMA, AMC1 and AMC2 are replaced by the number of 1,2 and $3 . M_{i j}(i, j=1,2,3)$ represent the working modes when $\Delta \varphi=180^{\circ}$ between two different unit cells. In this way, there will be five working modes of $M_{11}, M_{12}, M_{23}, M_{32}$ and $M_{13}$, as a result of perfect absorption for incidence of PMA, phase cancellation between PMA and AMC1, PMA and AMC2, AMC1 and AMC2, and AMC2 and AMC1. The RCS reduction bandwidth of the metasurface will be greatly expanded due to the cascade connection between five working modes.

\begin{tabular}{|c|c|c|c|c|c|c|}
\hline Parameters & $a$ & $w 2$ & $w 3$ & $b 1$ & $b 2$ & $b 3$ \\
\hline Dimensions (mm) & 10 & 9.7 & 5.4 & 2.4 & 3.4 & 8.5 \\
\hline
\end{tabular}

Tab. 1. Structure dimensions of the MS unit cells.

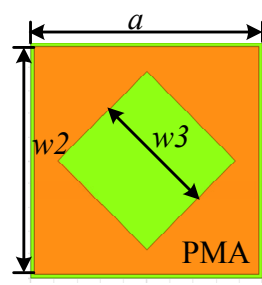

(a)

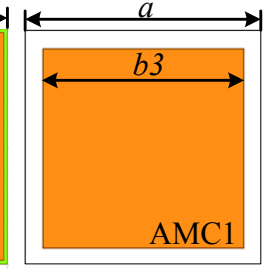

(b)

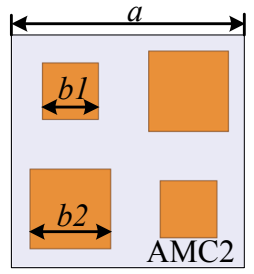

(c)
Fig. 1. Three kinds of MS unit cells. (a) PMA; (b) AMC1; (c) AMC2.

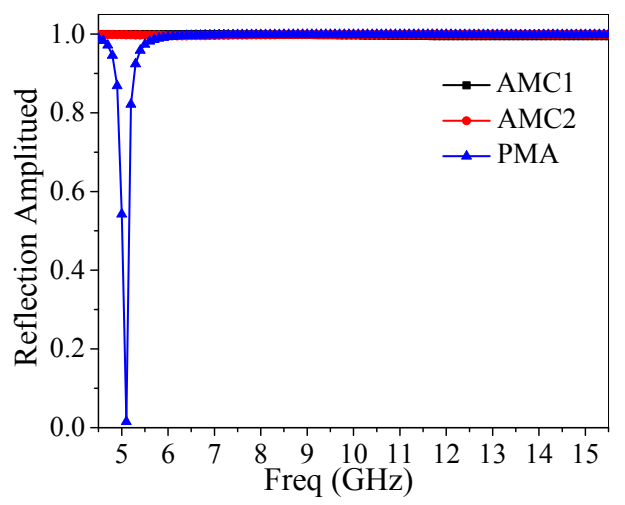

(a)

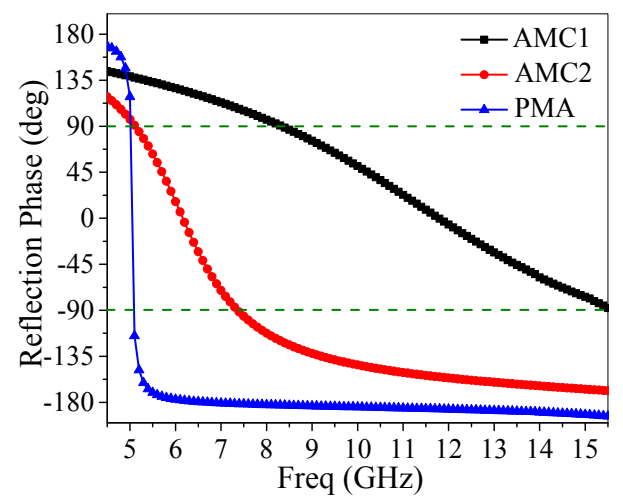

(b)

Fig. 2. Reflection characteristics of metamaterial units: (a) reflection amplitude; (b) reflection phase.

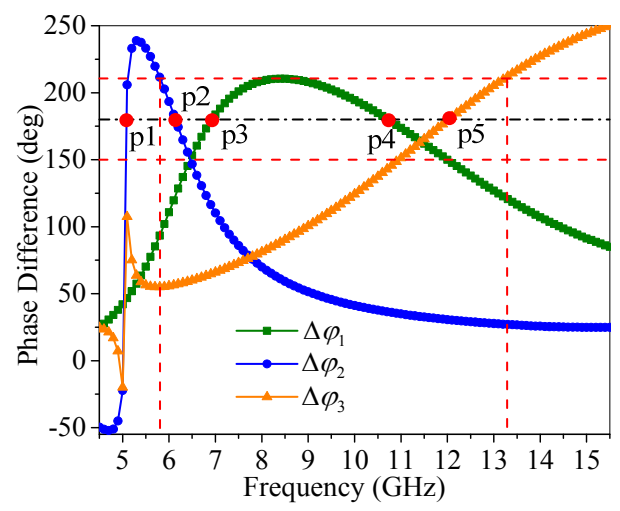

Fig. 3. Curves of phase differences between three kinds of units. 


\section{Design and Simulation of SA-MS}

\subsection{Array Design of SA-MS}

Considering the scattering pattern of a MS containing $U \times V$ elements, and which could be converted into the radiation pattern of an active array. According to the superposition principle of electromagnetic wave, the total scattering pattern of the MS can be expressed as:

$F(\theta, \varphi)=\sum_{u=1}^{U} \sum_{v=1}^{V} f_{u v}(\theta, \varphi)=$

$\sum_{u=1}^{U} \sum_{v=1}^{V} \exp \left\{\mathrm{j}\left(\frac{2 \pi}{\lambda} x_{u} \sin \theta \cos \varphi+\frac{2 \pi}{\lambda} y_{v} \sin \theta \sin \varphi\right)\right\} \cdot \exp \left(\mathrm{j} \varphi_{u v}\right)$

where $x_{u}=(u-(U-1) / 2) d_{u}, y_{v}=(v-(V+1) / 2) d_{v}, d_{u}$ and $d_{v}$ represent the center space between two adjacent elements along the $u$ - and $v$-axis, respectively. $\lambda$ is the wavelength of the incident wave. $\Phi_{\mathrm{uv}}$ represents the reflection phase of any element in the array.

Firstly, in order to maintain the periodicity of MS unit cells as well as avoid the amount of computation being too large, a lattice which contains $5 \times 5$ unit cells is generated. The three kinds of lattices construct a MS array including $4 \times 4$ lattices in a way of shared aperture. Meanwhile, the lattice of PMA not only needs to achieve the absorption for the incident wave, but also needs to accomplish the phase cancellation with the lattices of ACM1 and AMC2 at different frequency bands. Then, amount of the lattices of PMA, AMC1 and AMC2 is set as 6, 5 and 5 after considering the tandem of PMA and mutual dependence between the three MS lattices. Lastly, to make the value of $F(\theta, \varphi)$ minimum, the ergodic algorithm is employed to calculate all the cases of layout. Assuming 1,2 and 3 represent the lattices of $\mathrm{PMA}, \mathrm{AMC} 1$ and $\mathrm{AMC} 2$, respectively. As a result, the optimal layout of the SA-MS is:

$$
\left[\begin{array}{llll}
2 & 1 & 3 & 1 \\
3 & 2 & 1 & 3 \\
3 & 1 & 2 & 1 \\
1 & 2 & 2 & 3
\end{array}\right] .
$$

Based on (1), (2) and the reflection phase information from Fig. 2(b), we can quickly get the scattering pattern of

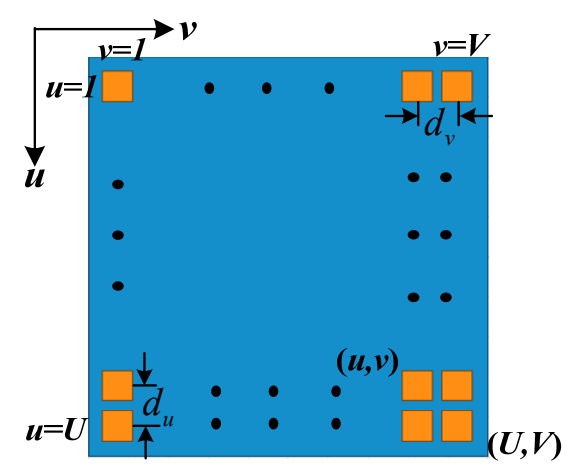

Fig. 4. Equivalent model of the SA-MS array. the SA-MS before the full wave simulation [23], [24]. For example, when $f=6.13 \mathrm{GHz}$, which means $d \approx \lambda, \varphi_{\mathrm{PMA}}=\pi$, $\varphi_{\mathrm{AMC} 1}=0, \varphi_{\mathrm{AMC} 2}=2 / 3 \pi$. The mode $M_{12}$ is excited due to the phase cancellation between PMA and AMC1. Then the scattering pattern in theory can be obtained in $0.36 \mathrm{~s}$ using the MATLAB 2013b, as shown in Fig. 5. It can be seen that the reflected energy flux is mainly distributed along the diagonal line compared to the PEC and the peak value is decreased from $16 \mathrm{~dB}$ to $7 \mathrm{~dB}$. The results verify the validity of the design method before the full wave simulation.

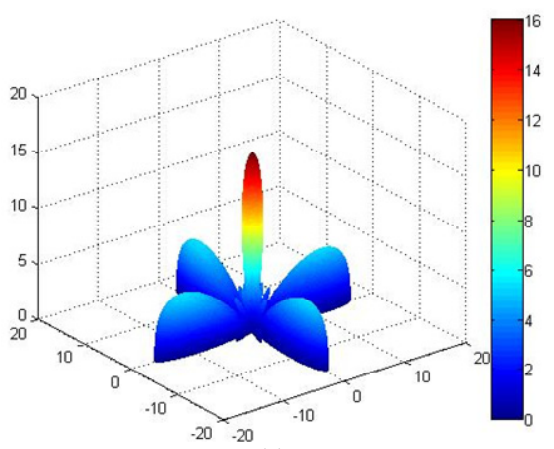

(a)

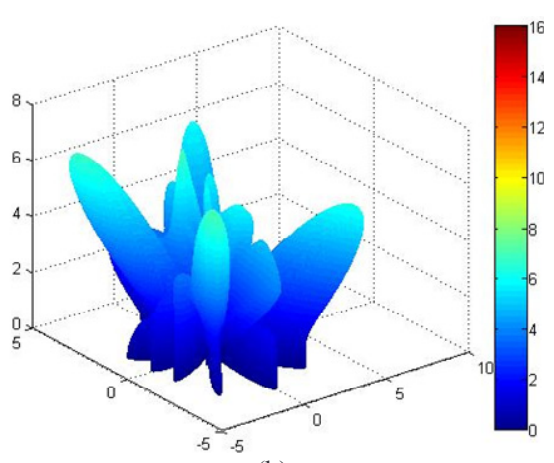

(b)

Fig. 5. Scattering pattern in theory at $6.13 \mathrm{GHz}$. (a) PEC; (b) SA-MS.

\subsection{Full Wave Simulation}

For a further study on scattering performances of the SA-MS, the structure model based on HFFSS14.0 is shown in Fig. 6. Figure 7 gives the RCS reduction curves of the SA-MS compared to the PEC under $\mathrm{x}$ - and y-polarized normal incident waves. From Fig. 7, the monostatic RCS of the SA-MS is reduced at least $3 \mathrm{~dB}$ from $4.88 \mathrm{GHz}$ to $14.36 \mathrm{GHz}$ for both $\mathrm{x}-$ and $\mathrm{y}$-polarizations. On the condition of $\mathrm{x}$ - polarization, except the few frequencies around $5.44 \mathrm{GHz}$, a more than $6 \mathrm{~dB}$ RCS reduction band is achieved from $4.86 \mathrm{GHz}$ to $12.44 \mathrm{GHz}$, while the bands are $5.04 \mathrm{GHz}-7.6 \mathrm{GHz}$ and $9.04 \mathrm{GHz}-12.64 \mathrm{GHz}$ on the condition of y-polarization. Meanwhile, it is known to us that the SA-MS possesses five modes including $M_{11}, M_{12}, M_{23}$, $M_{32}$ and $M_{13}$ at the frequency points of $f_{i}(i=1,2,3,4,5)$, respectively. Considering the case under x-polarization, for example, there are obvious reduction peaks when $f_{i}=$ $\left[f_{1}, f_{2}, f_{3}, f_{4}\right]=[5 \mathrm{GHz}, 6 \mathrm{GHz}, 7 \mathrm{GHz}, 10.52 \mathrm{GHz}]$ for the 


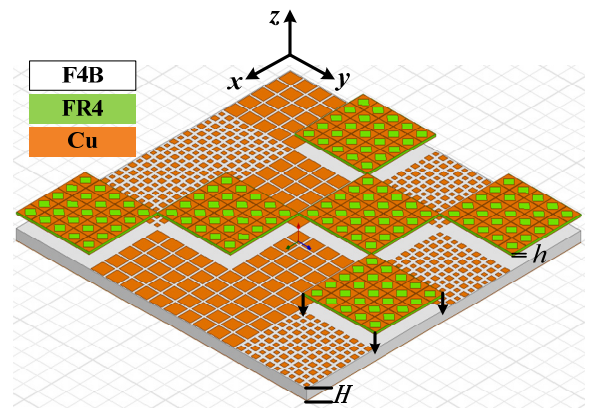

Fig. 6. Structure diagram of SA-MS.

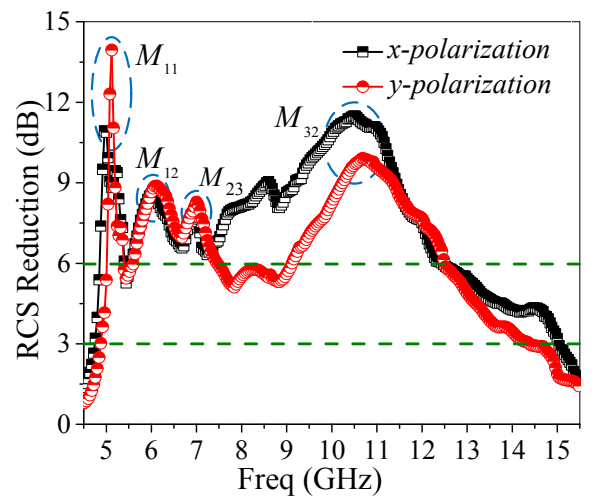

Fig. 7. RCS reduction curves of SA-MS.

curves in Fig. 7. It is anastomotic with the first four points proposed in Fig. 3, but the fifth mode $M_{13}$ is not driven. The problem can be attributed to electrically large dimension for the SA-MS at high frequency, increasing mutual coupling and higher-order mode.

Figure 8 provides the scattering patterns of PEC and SA-MS on the condition of x-polarized normal incidence at $5 \mathrm{GHz}, 6 \mathrm{GHz}, 7 \mathrm{GHz}$ and $10.52 \mathrm{GHz}$. When $f_{1}=5 \mathrm{GHz}$, the reflected energy is suppressed at the area of space where PMA located, which is attributed to perfect absorption for the incident wave of PMA. When $f_{2}=6 \mathrm{GHz}$, the phase cancellation between PMA and AMC1 decreases the reflection waves at the normal direction. When $f_{3}=7 \mathrm{GHz}$, the scattered energy flux is diffuse for the far-field pattern due to the phase cancellation at low frequency band between AMC1 and AMC2. When $f_{4}=10.52 \mathrm{GHz}$, the phase cancellation at high frequency band between $\mathrm{AMC1}$ and AMC2 diminishes the scattering field. At the same time, more reflected energy is lumped at the normal direction because PMA is equal to PEC at this time.

To further illustrate the mechanism of scattered field decreased, the surface E-field distributions of the SA-MS working at the modes of $M_{11}, M_{12}, M_{23}$ and $M_{32}$ are depicted in Fig. 9. From Fig. 9(a), lattices of PMA show strong electromagnetic resonance at $5 \mathrm{GHz}$, so RCS of the SA-MS is reduced due to their absorption for the incidence. From Fig. 9(b), lattices of AMC1 show the property of zero phase reflection at $6 \mathrm{GHz}$ due to its resonance under normal incidence. At this time, the reflection phase of PMA is $180^{\circ}$, so the phase cancellation occurs between PMA and AMC1. From Fig. 9(c), f or the $M_{23}$, the surface

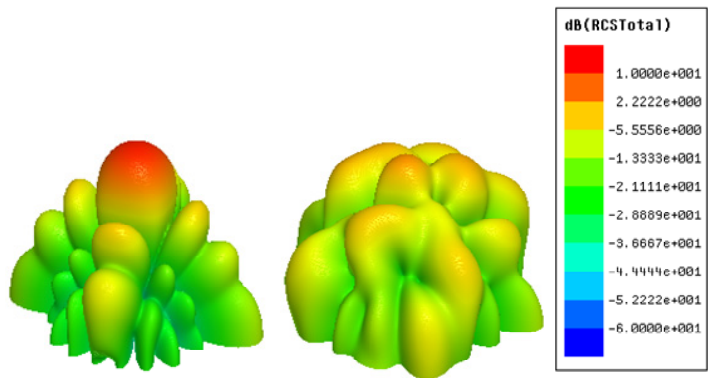

(a)

(b)

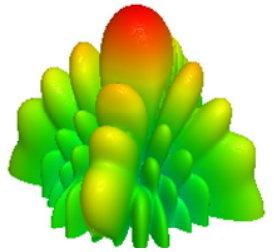

(c)

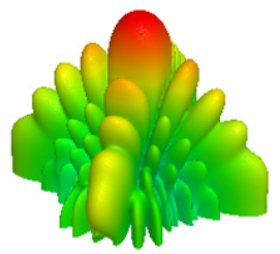

(e)

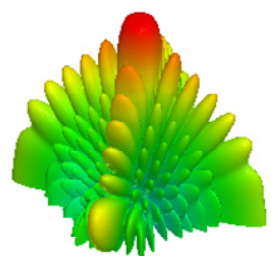

(g)

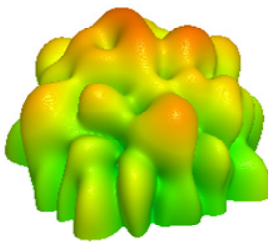

(d)

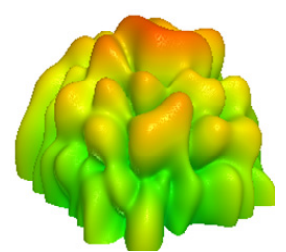

(f)

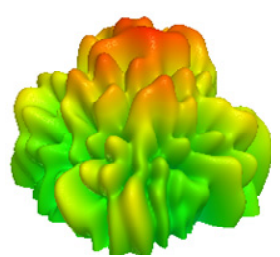

(h)
Fig. 8. Simulated 3-D scattering pattern under normal incident wave. (a) PEC at $5 \mathrm{GHz}$; (b) SA-MS at $5 \mathrm{GHz}$;

(c) $\mathrm{PEC}$ at $6 \mathrm{GHz}$; (d) SA-MS at $6 \mathrm{GHz}$;

(e) PEC at $7 \mathrm{GHz}$; (f) SA-MS at $7 \mathrm{GHz}$;

(g) PEC at $10.52 \mathrm{GHz}$; (h) SA-MS at $10.52 \mathrm{GHz}$.

E-field of AMC1 lattices is the greatest. Although it is not a 0-phase reflection for $\mathrm{AMC1}$, the phase difference between AMC1 and AMC2 is $180^{\circ}$, which can be inferred from Fig. 2(b). From Fig. 9(d), lattices of AMC2 show stronger electromagnetic resonance at $10.52 \mathrm{GHz}$, so the AMC2 reflects the incident wave with an almost changeless phase. Meanwhile, the reflection phase is close to $180^{\circ}$ for $\mathrm{AMC1}$, the phase cancellation between $\mathrm{AMC1}$ and AMC2 make RCS of the SA-MS reduced as a result.

\section{Fabrication and Measurement}

To verify the validity of the simulation results, the prototype of the SA-MS was fabricated and its reflectivity $\mathrm{S}_{21}$ was measured using the vector network analyzer at the anechoic chamber, as shown in Fig. 10. What is more, the distance between horn antennas and the sample is $1.6 \mathrm{~m}$, which is greater than the tenfold wavelength of the lowest measured frequency $4 \mathrm{GHz}$, meaning the condition of farfield test is satisfied. 


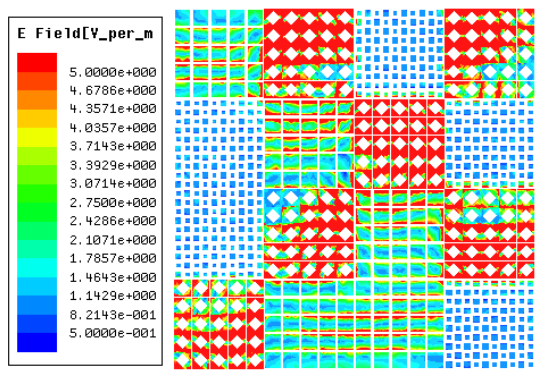

(a)

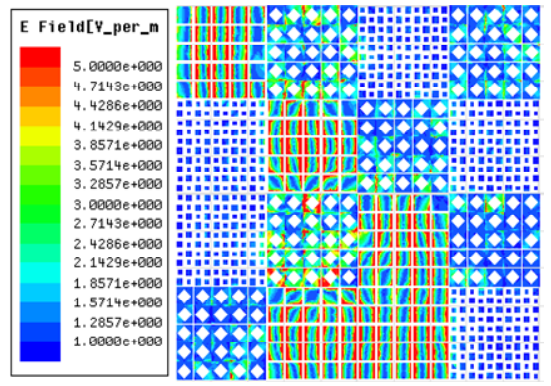

(b)

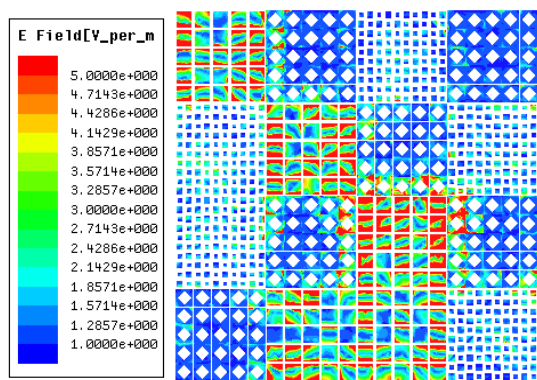

(c)

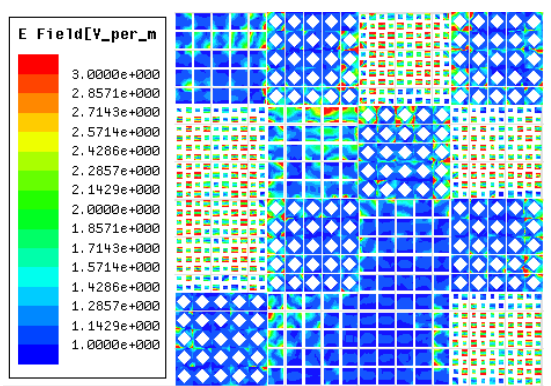

(d)

Fig. 9. Surface E-field distributions of SA-MS

(a) $M_{11}$ at $5 \mathrm{GHz}$; (b) $M_{12}$ at $6 \mathrm{GHz}$; (c) $M_{23}$ at $7 \mathrm{GHz}$; (d) $M_{32}$ at $10.52 \mathrm{GHz}$.

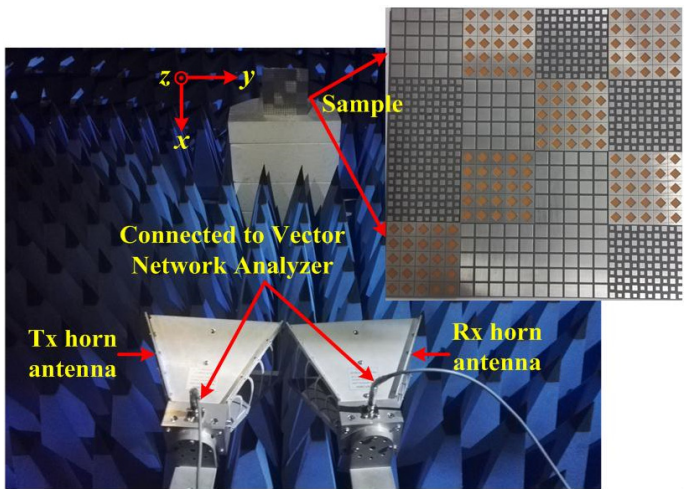

Fig. 10. The fabricated SA-MS and measurement setup.
Figure 11 gives the measured RCS reduction curves, from which we can observe that the fractional RCS reduction bandwidth (greater than $3 \mathrm{~dB}$ ) reaches $95.8 \%$ $(4.98 \mathrm{GHz}-14.14 \mathrm{GHz})$ for both $\mathrm{x}$ - and $\mathrm{y}$-polarized incidence. Additionally, for the $\mathrm{x}$-polarized waves, the band of $6 \mathrm{~dB}$ RCS reduction is $5.04 \mathrm{GHz}-13.02 \mathrm{GHz}$, while the bands are $5.06 \mathrm{GHz}-8.66 \mathrm{GHz}, 9.22 \mathrm{GHz}-12.12 \mathrm{GHz}$ on the condition of y-polarization. Contrast the measured results with the simulations, it can be found that the reduction bands and the peaks are coincident with each other. However, it should be noted that the measured curves are unstable at the range of $8 \mathrm{GHz}-12 \mathrm{GHz}$, which leads to the discontinuity of the $6 \mathrm{~dB}$ reduction bands for y-polarized incidence. This can be summarized as the fabrication errors, inaccurate angle between the sample and horn antennas, the experimental environment does not perfectly

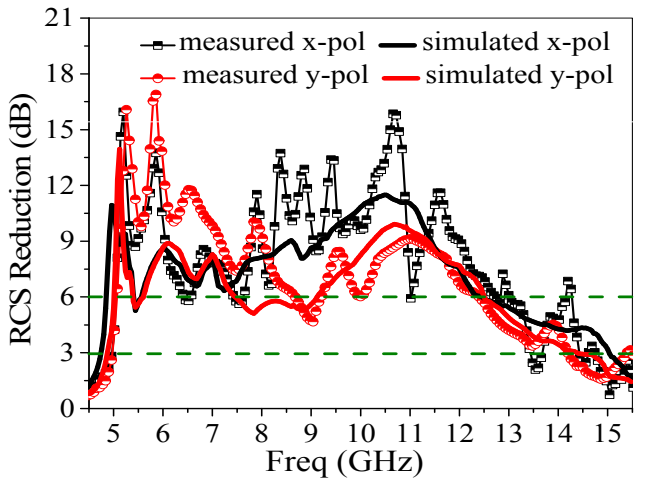

Fig. 11. Measured RCS reduction curves of SA-MS.

\begin{tabular}{|c|c|c|c|}
\hline $\begin{array}{c}\text { MS } \\
\text { structures }\end{array}$ & $\begin{array}{c}\text { Characteristics } \\
\text { of unit cell }\end{array}$ & Advantages & $\begin{array}{l}\text { Fractional } \\
\text { 6-dB RCS } \\
\text { reduction } \\
\text { bandwidth for } \\
\text { normal x-pol } \\
\end{array}$ \\
\hline $\begin{array}{l}\text { EBG in } \\
\text { Ref. [1] }\end{array}$ & $\begin{array}{l}\text { In-phase } \\
\text { reflection }\end{array}$ & Easy processing & $75.2 \%$ \\
\hline $\begin{array}{l}\text { HIS in } \\
\text { Ref. [2] }\end{array}$ & $\begin{array}{c}\text { Surface waves } \\
\text { suppression }\end{array}$ & Easy processing & Not mentioned \\
\hline $\begin{array}{l}\text { FSS in } \\
\text { Ref. [4] }\end{array}$ & $\begin{array}{l}\text { Band-pass or } \\
\text { band-stop }\end{array}$ & Easy processing & $66 \%$ \\
\hline $\begin{array}{l}\text { PRS in } \\
\text { Ref. [6] }\end{array}$ & $\begin{array}{l}\text { Polarization } \\
\text { conversion }\end{array}$ & Easy processing & $60.7 \%$ \\
\hline $\begin{array}{l}\text { SSPP in } \\
\text { Ref. [16] }\end{array}$ & $\begin{array}{l}\text { Transform the } \\
\text { incidence into } \\
\text { surface waves }\end{array}$ & $\begin{array}{l}\text { Independent of } \\
\text { the diffraction } \\
\text { limitation }\end{array}$ & $\begin{array}{c}90 \% \\
\text { (complicated } \\
\text { design) }\end{array}$ \\
\hline $\begin{array}{l}\text { AMC in } \\
\text { Ref. [9] }\end{array}$ & $\begin{array}{l}\text { In-phase } \\
\text { reflection }\end{array}$ & $\begin{array}{l}\text { Easy processing } \\
\text { Flexible to } \\
\text { manipulate the } \\
\text { reflection phase }\end{array}$ & $52.1 \%$ \\
\hline $\begin{array}{l}\text { PMA in } \\
\text { Ref. [12] }\end{array}$ & $\begin{array}{c}\text { Perfect } \\
\text { absorption }\end{array}$ & $\begin{array}{l}\text { Extremely low } \\
\text { profile }\end{array}$ & $2.1 \%$ \\
\hline $\begin{array}{l}\text { SA-MS in } \\
\text { this paper }\end{array}$ & $\begin{array}{l}\text { In-phase } \\
\text { reflection; } \\
\text { Perfect } \\
\text { absorption }\end{array}$ & $\begin{array}{c}\text { Easy processing; } \\
\text { Efficient } \\
\text { utilization with } \\
\text { phase } \\
\text { information of } \\
\text { PMA and AMC }\end{array}$ & $88.4 \%$ \\
\hline
\end{tabular}

Tab. 2. Comparison between different MS structures 
satisfy the condition of ideal Compact Antenna Test Range (CATR) and so on. After repetitive measurements, the measured results are in reasonable agreement with the simulations. In summary, the property of wideband lowscattering of the SA-MS is confirmed.

Lastly, we provide the comparison between different MS structures stated in the Introduction and the proposed SA-MS, as shown in Tab. 2. It can be seen that the RCS reduction bandwidth of SA-MS has been distinctly expanded after arranging PMA and AMC in shared aperture with an aperiodic arrangement. In addition, the SA-MS can achieve RCS reduction in multiple approaches due to its multiple characteristics of unit cell, which include phase cancellation and perfect absorption.

\section{Conclusion}

In this paper, we propose a novel method to design a MS with the property of wideband low-scattering. The simulated and experimental results both can verify the availability of this idea after arranging the lattices of PMA and AMC in shared aperture. In a word, the research findings enrich and develop the methods of designing the wideband low-scattering MS.

\section{Acknowledgements}

This work is supported by the National Natural Science Foundation of China (No. 61471389, No. 61501494, and No. 61671464) and the Doctoral Foundation of Air Force Engineering University (No. KGD08091601). Authors also thank the reviewers for their valuable comments.

\section{References}

[1] CHEN, W., BALANIS, C., BIRTCHER, C. Checkerboard EBG surfaces for wideband radar cross section reduction. IEEE Transactions on Antennas and Propagation, 2015, vol. 63, no. 6, p. 2636-2645. DOI: 10.1109/TAP.2015.2414440

[2] COSTRA, F., MONORCHIO, A., TALARICO, S., et al. An active high-impedance surface for low-profile tunable and steerable antennas. IEEE Antennas and Wireless Propagation Letters, 2008, vol. 7, p. 676-680. DOI: 10.1109/LAWP.2008. 2006070

[3] LIU, Y., HAO, Y., WANG, H., et al. Low RCS microstrip patch antenna using frequency-selective surface and microstrip resonator. IEEE Antennas and Wireless Propagation Letters, 2015, vol. 14, p. 1290-1293. DOI: 10.1109/LAWP.2015.2402292

[4] EDALATI, A., SARABANDI, K. Wideband, wide angle, polarization independent RCS reduction using nonabsorptive miniaturized-element frequency selective surfaces. IEEE Transactions on Antennas and Propagation, 2014, vol. 62, no. 2, p. 747-754. DOI: 10.1109/TAP.2013.2291236

[5] ZHANG, Z., CAO, X., GAO, J., et al. Broadband metamaterial reflectors for polarization manipulation based on cross/ring resonators. Radioengineering, 2016, vol. 25, no. 3, p. 436-441. DOI: $10.13164 /$ re.2016.0436

[6] JIA, Y., LIU, Y., GUO, J., et al. Broadband polarization rotation reflective surfaces and their applications to RCS reduction. IEEE Transactions on Antennas and Propagation, 2016, vol. 64, no. 1, p. 179-188. DOI: 10.1109/TAP.2015.2502981

[7] SIEVENPIPER, D., ZHANG, R. F., BROAS, R. F. J., et al. Highimpedance electromagnetic surfaces with forbidden bands at radio and microwave frequencies. IEEE Transactions on Microwave Theory and Techniques, 1999, vol. 47, no. 11, p. 2059-2084. DOI: $10.1109 / 22.798001$

[8] PAQUAY, M., IRIARTE, J. C., EDERRA, I., et al. Thin AMC structure for radar cross-section reduction. IEEE Transactions on Antennas and Propagation, 2007, vol. 55, no. 12, p. 3630-3638. DOI: 10.1109/TAP.2007.910306

[9] HONG, T., DONG, H., WANG, J., et al. A novel combinatorial triangle-type AMC structure for RCS reduction. Microwave and Optical Technology Letters, 2015, vol. 57, no. 12, p. 2728-2732. DOI: $10.1002 /$ mop.29427

[10] MIGHANI, M., DADASHZADEH, G. Broadband RCS reduction using a novel double layer chessboard AMC surface. Electronics Letters, 2016, vol. 52, no. 14, p. 1253-1255. DOI: 10.1049/el.2016.1214

[11] LANDY, N. I., SAJUYIGBE, S., MOCK, J. J., et al. Perfect metamaterial absorber. Physical Review Letter, 2008, vol. 100, no. 20, p. 207402. DOI: 10.1103/PhysRevLett.100.207402

[12] YANG, H., CAO, X., GAO, J., et al. Design of low-radar cross section microstrip antenna based on metamaterial absorber. Acta Physica Sinica, 2013, vol. 62, no. 6, p. 064103. (in Chinese) DOI: 10.7498/aps.62.064103

[13] USTUN, K., TURHAN-SAYAN, G. Wideband long wave infrared metamaterial absorbers based on silicon nitride. Journal of Applied Physics, 2016, vol. 120, p. 203101(1-11). DOI: $10.1063 / 1.4968014$

[14] KUZNETSOV, S. A., PAUlish, A. G., NAVARRO-CIA, M., et al. Selective pyroelectric detection of millimeter waves using ultrathin metasurface absorbers. Scientific Reports, 2016, vol. 6, 11 p. DOI: $10.1038 /$ srep2 1079

[15] MA, H., SHEN, X., CHENG, Q., et al. Broadband and highefficiency conversion from guided waves to spoof surface plasmon polaritons. Laser and Photonics Review, 2014, vol. 8, no. 1, p. 146-151. DOI: 10.1002/lpor.201300118

[16] LI, S., CAO, X., GAO, J., et al. Polarization-insensitive ultra-thin quasi-metasurface based on the spoof surface plasmon polaritons. Applied Physics A, 2016, vol. 12, p. 857(1-9). DOI: 10.1007/s00339-016-0391-2

[17] ZHAO, Y., CAO, X., GAO, J., et al. Broadband low-RCS metasurface and its application on antenna. IEEE Transactions on Antennas and Propagation, 2016, vol. 64, no. 7, p. 2954-2962. DOI: $10.1109 /$ TAP.2016.2562665

[18] IRIARTE-GALARREGUI, J., TELLECHEA-PEREDA, A., MARTINEZ DE FALCON, J. L., et al. Broadband radar crosssection reduction using AMC technology. IEEE Transactions on Antennas and Propagation, 2013, vol. 61, no. 12, p. 6136-6143. DOI: 10.1109/TAP.2013.2282915

[19] WAN, X., QI, M., CHEN, T., et al. Field-programmable beam reconfiguring based on digitally-controlled coding metasurface. Scientific Reports, 2016, vol. 6, 8 p. DOI: 10.1038/srep20663

[20] ZOU, T. B., HU, F. R., XIAO, J., et al. Design of a polarizationinsensitive and broadband terahertz absorber using metamaterials. Acta Physica Sinica, 2014, vol. 63, no. 17, p. 178103. (in Chinese) DOI: 10.7498/aps.63.178103 
[21] ZHU, J., MA, Z., SUN, W., et al. Ultra-broadband terahertz metamaterial absorber. Applied Physics Letters, 2014, vol. 105, no. 021102 . DOI: $10.1063 / 1.4890521$

[22] CHENG, Y., NIE, Y., GONG, R. A polarization-insensitive and omnidirectional broadband terahertz metamaterial absorber based on coplanar multi-squares films. Optics \& Laser Technology, 2013, vol. 48, no. 10, p. 415-421. DOI: 10.1016/j.optlastec.2012.11.016

[23] JAYASINGHE, J., ANGUERA, J., UDUWAWALA, D. Genetic algorithm optimization of a high-directivity microstrip patch antenna having a rectangular profile. Radioengineering, 2013, vol. 22 , no. 3, p. 700-707.

[24] JAYASINGHE, J., ANGUERA, J., UDUWAWALA, D. A highdirectivity microstrip patch antenna design by using genetic algorithm optimization. Progress In Electromagnetics Research C, 2013, vol. 37, no. 4, p. 131-144. DOI: 10.2528/PIERC13010805

\section{About the Authors ...}

Tong HAN was born in Yuncheng, Shannxi province in 1993. He received the B.S. degree from the Air Force Engineering University in 2015. He currently works towards the M.S. degree at the Information and Navigation College. His research interests mainly include the design of shared aperture metasurface for wideband RCS reduction and its application on antennas.

Xiangyu CAO received the B.Sc and M.A.Sc degrees from the Air Force Missile Institute in 1986 and 1989, respectively. She joined the Air Force Missile Institute in
1989 as an assistant teacher. She became an associate professor in 1996. She received Ph.D. degree from the Missile Institute of the Air Force Engineering University in 1999. From 1999 to 2002, she was engaged in postdoctoral research in Xidian University, China. She was a Senior Research Associate in the Dept. of Electronic Engineering, City University of Hong Kong from Jun. 2002 to Dec. 2003. She is currently a professor of the Air Force Engineering University of CPLA. Her research interests include computational electromagnetics, smart antennas, electromagnetic metamaterial and their antenna applications, and electromagnetic compatibility.

Jun GAO received the B.Sc and M.A.Sc degrees from the Air Force Missile Institute in 1984 and 1987, respectively. He joined the Air Force Missile Institute in 1987 as an assistant teacher. He became an associate professor in 2000. $\mathrm{He}$ is currently a professor of the Information and Navigation College, Air Force Engineering University of CPLA. He has authored and coauthored more than 100 technical journal articles and conference papers, and holds one China soft patent. His research interests include smart antennas, electromagnetic metamaterials and their antenna applications.

Yuejun ZHENG received his M.S. degree from AFEU in 2013. He is currently working towards the Ph.D. degree. His research interests include microstrip antennas and electromagnetic scattering theory. 